\title{
Antimicrobial Activity of Chitosan Film Forming Solution Enriched with Essential Oils; an in Vitro Assay
}

\author{
Kana Jean Raphaël ${ }^{1}$ and Amir Meimandipour ${ }^{* 2}$ \\ ${ }^{1}$ Department of Animal Productions, Faculty of Agronomy and Agricultural Sciences, University of Dschang, 70 Dschang, Cameroon \\ ${ }^{2}$ Department of Animal Biotechnology, National Institute of Genetic Engineering and Biotechnology, Tehran, 14965/161, Iran
}

\begin{abstract}
"Corresponding author: Amir Meimandipour, Department of Animal Biotechnology, National Institute of Genetic Engineering and Biotechnology, Tehran, Iran. Tel: +98-2144787459, Fax: +98-2144787395, E-mail: meimandi@nigeb.ac.ir

Received: 25 Oct. 2015; Revised:2 July 2016; $\quad$ Accepted: 19 June 2017 ; $\quad$ Published online: 19 August 2017
\end{abstract}

Background: The resistance of the bacteria and fungi to the innumerous antimicrobial agents is a major challenge in the treatment of the infections demands to the necessity for searching and finding new sources of substances with antimicrobial properties. The incorporation of the essential oils (EOs) in chitosan film forming solution may enhance antimicrobial properties. However, its use as the feeding additive in the poultry nutrition needs to clarify the product's activity against both pathogen and the useful microbes in the gastrointestinal tract.

Objectives: In the present study, we carried out an in vitro investigation and evaluated the antimicrobial activity of chitosan film forming solution incorporated with essential oils (CFs+EOs) against microbial strains including Staphylococcus aureus, Escherichia coli, Enterococcus faecium, Lactobacillus rahmnosus, Aspergillus niger and Alternaria alternate.

Material and Methods: In three replicates, the minimum inhibitory concentration (MIC) and the minimum bactericidal concentration (MBC) of different treatments including: 1- essential oils (EOs), 2- chitosan film solution (CFs), and 3-chitosan film solution enriched with EOs (CFs+EOs) were determined against above mentioned microbes.

Results: The results indicated that the chitosan solution enriched with essential oils (CFs+EOs) is capable of inhibiting the bacterial and fungal growth even at the lowest concentrations. The MIC and MBC for all the antimicrobial agents against Escherichia coli and Staphylococcus aureus were very low compared to the concentrations needed to inhibit the growth of useful bacteria, Lactobacillus rahmnosus and Enterococcus faecium. The antifungal activity of chitosan was enhanced as the concentration of EOs increased in the film solution.

Conclusion: Chitosan-EOs complexes are the promising candidate for novel contact antimicrobial agents that can be used in animal feeds.

Keywords: Antimicrobial properties; Bacteria; Chitosan, Chitosan film forming solution; Essential oils; Fungi

\section{Background}

There are many phytobiotics that emerged into the market that have the potential to increase the growth performances of the chickens. These phytobiotics include spices, plant extracts, and essential oils (EOs). Essential oils are volatile compounds that are found in aromatic plants all over the world. They are sources of biologically active compounds with strong antibacterial, antioxidant, and digestion stimulating abilities (1-2). The use of these volatile compounds as feed additives (3-7) has become an attractive area of research in poultry science. Essential oils from a variety of the plants have been shown to stimulate feed intake and digestion, improve body weight gain, support of a positive gut microflora, and offer healthy performance benefits to poultry (8-9). The enhancement of the animal growth performance by EOs is due to the reduction of pathogens within the intestine with direct consequence of increasing nutrient availability for animal utilization due to the lower nutrient competition and intestinal diseases prevention (1). The other beneficial effects of the supplementing animal feed with EOs include stimulation of appetite, improvement of digestive enzyme secretion, immune system modulation, antimicrobial activity and decreased mortality $(7,10-$ 13). As well, there is a synergism when several EOs 
are mixed, the result of which is a greater antimicrobial effect than individual EOs alone $(1-2,14)$.

Due to their oxidative and volatile properties in addition to their susceptibility to high temperatures, EOs have a tendency to lose their efficiency due to the mitigated quality. The main components of EOs are labile, volatile, and most of them are easily lost during feed processing and storage. Under different storage conditions and environmental variation, EOs degrades rapidly when compared to chemotherapics. The volatile property of EOs causes a large loss in the quantity of the product during feed processing and storage. Incorporation in a stable matrix can overcome the technical issues of stability and odour in the feed (15). Moreover, incorporation in a matrix can stabilize and avoid loss of EOs quality and quantity in animal feed formulation. It may also lead to flavor optimization of the feed, better handling, reduce dustiness and increase stability, delay in the release of EOs in the digestive tract, and enhancement of bioavailability (16). In this regard, hydrophilic nanoparticles of chitosan having the capacity to bind varieties of biomolecules have recently attracted attentions in the human food industry.

Chitosan is a natural biodegradable and biocompatible non-toxic polymer extracted from crustacean shells having the potential to efficiently retain the bioactivity of molecules such as nucleic acids, proteins, and antigens (17-21). In addition, it also presents immune-stimulating, antimicrobial, wound-healing properties (22-25). In addition, it has recently been used as the vaccine delivery systems (26-27) as well as volatile feed additives compounds such as EOs in animal feed (15). Their antimicrobial property is effective only in aqueous systems and this property becomes inefficient in its insoluble film aspect (28). In the later aspect, chitosan constitutes a barrier capable of reducing respiration and retards bacterial and fungal growth (29-30). According to Ruiz-Navajas et al. (33), chitosan film solutions enriched with EOs enhance the chitosan antimicrobial properties and stabilize lipid in the feed. Up to now, few studies have been reported about chitosancompounded fragrance for animal feed. Mixing chitosan with EOs could allow them to exert their in vivo antimicrobial and digestive-stimulating activities by ensuring a more efficient delivery to the target site in the gastrointestinal tract.

\section{Objectives}

The present in vitro study was proposed to give an overview on the potential of chitosan film for retaining and protecting the essential oil bioactivity and for evaluating the benefits of the association chitosanessential oil toward supporting a positive gut microfloral growth.

\section{Materials and Methods}

\subsection{Materials}

Medium molecular weight chitosan [Poly (D-glucosamine)] was provided from Sigma-Aldrich (St. Louis, MO, USA). MRS broth, Nutrient broth, and Sabouraud Dextrose broth were procured from Iranian Bioresearch CO. All reagents used in this study were of analytical grade. Oregano and thyme essential oils were procured from Barij Esans Co. Iran. In the experiment, all solutions were prepared with distilled water.

\subsection{Preparation of Chitosan Film (CFs) and Chitosan} Film Incorporated with Essential Oils- (CFs+EOs) Solutions

Chitosan films solution (CFs) were prepared according to Chi et al. (28) with modification. Chitosan stock solution $(1 \%(\mathrm{w} / \mathrm{v}))$ was prepared under magnetic stirring by dissolving $1 \mathrm{~g}$ of chitosan in $100 \mathrm{~mL}$ of an aqueous acetic acid solution $(1 \%(\mathrm{v} / \mathrm{v}))$ at ambient temperature overnight. A blend of Oregano (500 $\mu \mathrm{L})$ and Thyme $(500 \mu \mathrm{L})$ EOs was mixed with 500 $\mu \mathrm{L}$ of tween 20 and introduced in the chitosan stock solution under constant stirring. The final essential oilsloaded chitosan film forming solution consisted of $1 \%$ chitosan, $1 \%$ acetic acid, $0.5 \%$ Tween 20 , and $1 \%$ EOs. The freshly prepared CFs and CF+EOs solutions were used for antimicrobial assays.

\subsection{Structure of Chitosan Films}

FTIR spectra of chitosan powder, chitosan films (CFs), EOs-loaded chitosan film (CFs+EOs), Thyme EO, Oregano EO and blend of Thyme and Oregano EOs were recorded to evaluate the cross-linking of chitosan with EOs in the film. FTIR spectra were recorded on a BRUKER FTIR spectrophotometer (TENSOR 27, Germany) using potassium bromide ( $\mathrm{KBr}$ ) pellets at a resolution of $4 \mathrm{~cm}^{-1}$.

\subsection{Preparation of Antimicrobial Essential Oil Solution}

A blend of the EOs solution was prepared by mixing $2.5 \mathrm{~mL}$ of Oregano and $2.5 \mathrm{~mL}$ of Thyme essential oils in $2.5 \mathrm{~mL}$ of tween 20. Then, the mixture of EOs-tween 20 was added to $100 \mathrm{~mL}$ distilled water under magnetic stirring for $30 \mathrm{~min}$ and used for antimicrobial assays. CFs and EOs solutions were used as control samples for testing the antimicrobial activity of CFs+EOs. The concentrations of EOs in the solution was tested 
ranging from 50 to $0.39 \mu \mathrm{L} \cdot \mathrm{mL}^{-1}(50,25,12.5,6.25$, $3.12,1.56,0.78$ and $0.39 \mu \mathrm{L} \cdot \mathrm{mL}^{-1}$ ) while in CFs+EOs solution, EOs concentrations was ranged from 10 to $0.078 \mu \mathrm{L} . \mathrm{mL}^{-1}(10,5,2.5,1.25,0.625,0.312,0.156$ and $\left.0.078 \mu \mathrm{L} \cdot \mathrm{mL}^{-1}\right)$.

\subsection{Microbial Strains}

Inhibition assays were carried out with pure cultures of the bacterial and fungal strains. A total of four different bacteria were used; three grams of the positive and one gram of the negative genera. The Gram positive strains were Enterococcus faecium (PTCC 1237), Lactobacillus rahmnosus (PTCC 1637) and Staphylococcus aureus (PTCC 1189). A Gram negative bacterium was Escherichia coli (PTCC 1399). To prepare the stock cultures, Enterococcus faecium and Lactobacillus rahmnosus were grown in MRS agar and Staphylococcus aureus and Escherichia coli were grown on nutrient agar and were stored under refrigeration condition at $4-8{ }^{\circ} \mathrm{C}$ and subcultured weekly. Two molds, Aspergillus niger (PTCC 5154) and Alternaria alternata (PTCC 5224) were also tested. Cultures were grown in Sabouraud Dextrose Agar and stored under refrigerated conditions at $4-8{ }^{\circ} \mathrm{C}$ and subcultured weekly. All test micro-organisms were obtained from the culture collection of the National Institute of Genetic Engineering and Biotechnology (NIGEB), Tehran, Iran.

\subsection{Antimicrobial Activity Assessment}

The minimum inhibitory concentration (MIC) and the minimum bactericidal concentration (MBC) of $\mathrm{CFs}, \mathrm{CFs}+\mathrm{EOs}$ and EOs solutions were determined as described by Qi et al. (22). Briefly, a number of test tubes, each containing $5.0 \mathrm{~mL}$ of MRS broth as culture media for Enterococcus faecium and Lactobacillus rahmnosus, and nutrient broth for Escherichia coli and Staphylococcus aureus were autoclaved for 15 $\min$ at $121{ }^{\circ} \mathrm{C}$. To the first tube of each, $5.0 \mathrm{~mL}$ of $\mathrm{CFs}, \mathrm{CFs}+\mathrm{EOs}$ or EOs solutions as prepared above was respectively added. After mixing, $5.0 \mathrm{~mL}$ of the mixture was transferred to the second tube, and similar transformations were repeated. Each tube contained a test sample solution with half of the concentration of the previous one. The tubes were inoculated under aseptic conditions with $50 \mu \mathrm{L}\left(1 \times 10^{7}\right.$ CFU.mL $\left.{ }^{-1}\right)$ of the freshly prepared bacterial suspension and incubated in an orbital shaker $(180 \mathrm{rpm})$ at $37^{\circ} \mathrm{C}$ for $20 \mathrm{~h}$. The control tubes were contained only MRS broth and nutrient broth. After incubation, a loopful from each tube was cultured on its relevant culture medium and incubated at $37^{\circ} \mathrm{C}$ for $24 \mathrm{~h}$.
The MIC was defined as the lowest concentration of compound that completely inhibited visible growth of bacteria. The MBC was defined as the lowest concentration of $\mathrm{CFs}, \mathrm{CFs}+\mathrm{EOs}$, and EOs that kills all the bacteria, resulting in no growth on subculture.

\subsection{Antifungal Activity Assay}

Chitosan film (CFs), chitosan film enriched with EOs (CFs+EOs) and pure essential oils (EOs) solutions were screened for antifungal activity against Aspergillus niger and Alternaria alternata by observing the percentage inhibition of mycelial growth under their effect according to a method modified from the procedure reported by Kaur et al. (25). About $20 \mathrm{~mL}$ of the Sabouraud Dextrose Agar (SDA) medium was poured into Petri plates and allowed to solidify. After solidification, $1 \mathrm{~mL}$ of CFs, CFs+EOs, and EOs stock solution were spread on top using a sterilized swab and were dried for $10 \mathrm{~min} .5 \mathrm{~mm}$ discs of a 7-days-old culture of the test fungi were placed at the center of the above Petri plates and incubated at $37^{\circ} \mathrm{C}$ for $96 \mathrm{~h}$. After incubation, the diameter $(\mathrm{mm})$ of the grown colony was measured. For each treatment, three replicates were maintained. Sabouraud Dextrose Agar medium without the CFs, CFs+EOs, and EOs solution served as control. The minimal inhibitory concentration (MIC) of each compound was defined as the lowest concentration of compound that completely inhibited visible growth after $96 \mathrm{~h}$ of incubation. The minimal fungicidal concentration (MFC) was defined as the lowest concentration resulting in no growth on subculture.

The toxicity of these solutions to fungi in terms of percentage inhibition of mycelial growth was calculated using the formula:

$\%$ Inhibition $=(\mathrm{dc}-\mathrm{dt}) / \mathrm{dc} \times 100$

Where, $\mathrm{dc}=$ average increase in mycelial growth in control, $\mathrm{dt}=$ average increase in mycelial growth under treatment.

\section{Results}

\subsection{FTIR Analysis}

FTIR spectra of Thyme and Oregano EOs, Cs, CFs, $\mathrm{CFs}+\mathrm{EO}$ s were recorded to investigate $\mathrm{CF}$ and ThymeOregano EOs interactions. The results of FTIR spectra are shown in Figures 1 and 2, and the main bands are shown in Table 1. Thyme and oregano essential oils show characteristics peaks at 3397 and 3402 (hydrogen bonded $\mathrm{OH}$ stretching overlapped with $\mathrm{N}-\mathrm{H}$ stretching bands), respectively. These peaks are joined, increased 


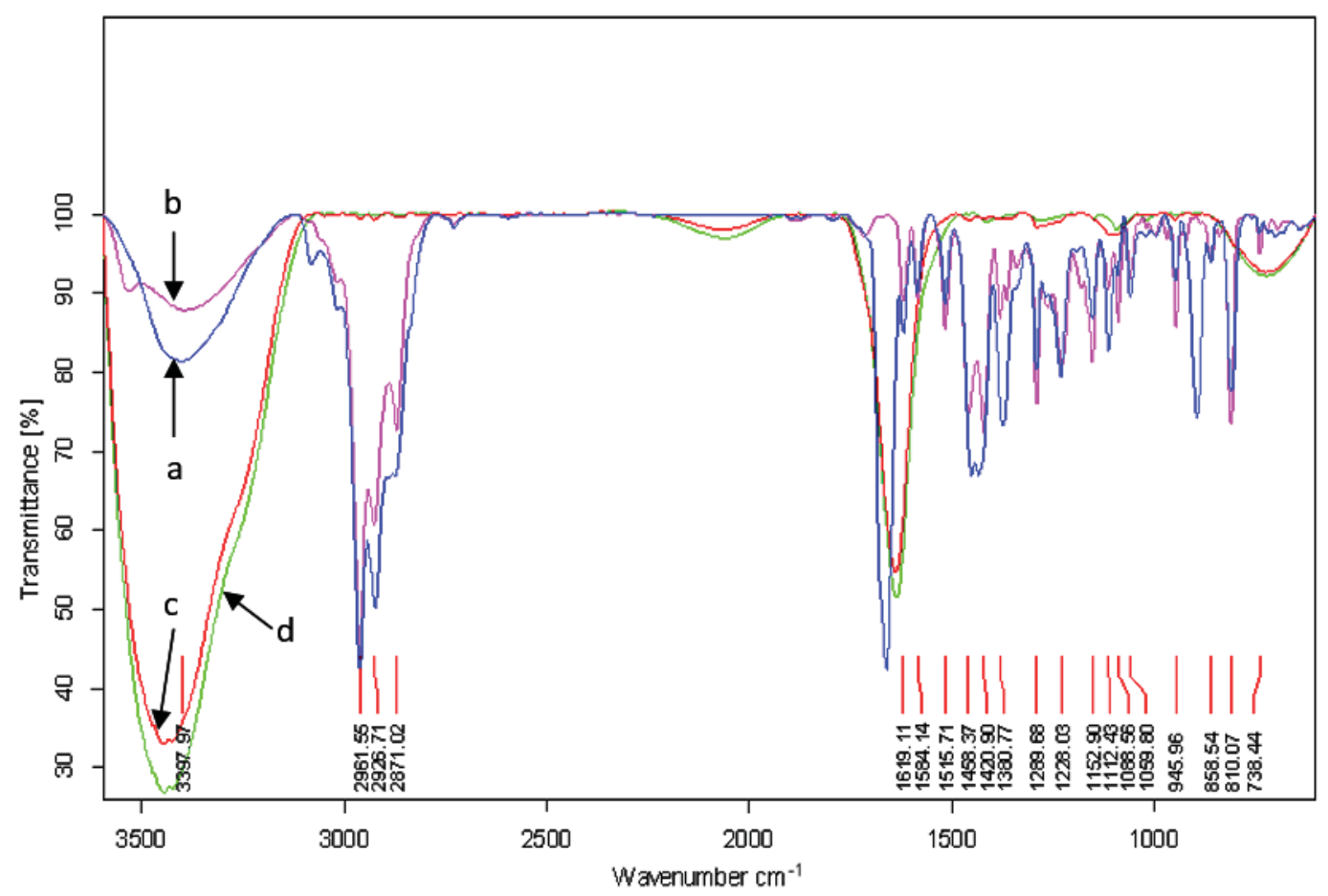

Figure 1. FTIR spectra of (a) Oregano EO, (b) Thyme EO, (c) the blend of Thyme and Oregano EOs, and (d) EOs loaded-chitosan film. The peaks show the presence of interaction in between two EOs in mixture.

in the intensity of the $\mathrm{OH}$ and $\mathrm{NH}$ stretching in a single peak at 3443 indicating an increase in the content of ester groups when thyme and oregano EOs are mixed together (Fig. 1). The crosslink between EOs shows characteristics peaks at 1638 (amide I) and 723 (C-O stretching) resulting from many peaks found in the individual EO which merged to a single peak when EOs are mixed in tween 20 . It should be noted that the $\mathrm{OH}$ and N-H stretching bands around $3443 \mathrm{~cm}^{-1}$ remained undisturbed when EOs are added in chitosan film solution.

Chitosan powder shows the characteristic peak at $3296 \mathrm{~cm}^{-1}$ corresponding to the combined peaks of the $\mathrm{OH}$ and $\mathrm{NH} 2$ groups stretching vibration in chitosan
(Fig. 2). A change in the relative intensity of this band was observed when EOs was incorporated in the chitosan films solution. A shift from 3296 to $3443 \mathrm{~cm}^{-1}$ is shown in EOs-loaded chitosan film solution indicates that the hydroxyl groups and amine groups of the chitosan might involve in some interactions after incorporation of EOs to the chitosan. In chitosan powder, the bands at 1662 and $1596 \mathrm{~cm}^{-1}$ were attributed to amide $\mathrm{I}(\mathrm{C}=\mathrm{O}$ stretching) and amide II (N-H bending modes) groups, respectively, joined and shifted to 1636 in the EOsloaded chitosan film solution suggesting the crosslink of EOs to nitrogen atoms of chitosan. Peaks found in chitosan powder at 895 and $664 \mathrm{~cm}^{-1}$ joined and shifted to a new band at $722 \mathrm{~cm}^{-1}$ in EOs-loaded chitosan film

Table 1. Main IR bands $\left(\mathrm{Cm}^{-1}\right)$ of Cs Powder, CFs+EOs, Thyme EO, Oregano EO, and a blend of Thyme and Oregano EOs.

\begin{tabular}{lccccc}
\hline $\begin{array}{l}\text { Wave number } \\
\left(\mathbf{c m}^{-1}\right)\end{array}$ & $\begin{array}{c}\text { Thyme EO } \\
\left(\mathbf{v . c m} \mathbf{-}^{-1}\right)\end{array}$ & $\begin{array}{c}\text { Oregano EO } \\
(\mathbf{v . c m})\end{array}$ & $\begin{array}{c}\text { Thyme+Oregano EOs } \\
\left(\mathbf{v . c m} \mathbf{-}^{-1}\right)\end{array}$ & $\begin{array}{c}\text { Cs Powder } \\
\left(\mathbf{v . c m}^{-1}\right)\end{array}$ & $\begin{array}{c}\mathbf{C F s}+\mathbf{E O s} \\
(\mathbf{v . c m})\end{array}$ \\
\hline $3000-3500$ & 3397 & 3402 & 3443 & 3296 & 3443 \\
$2500-3000$ & $2961-2926-$ & $2961-2924$ & $/$ & 2873 & $/$ \\
$1500-2000$ & $1619-1584$ & $1680-1618$ & 1638 & $1662-1596$ & 1636 \\
$1000-1500$ & $1458-1380$ & $1451-1374$ & $/$ & $1424-1382-$ & $/$ \\
$500-1000$ & 738 & 808 & 723 & $895-664$ & 722 \\
\hline
\end{tabular}




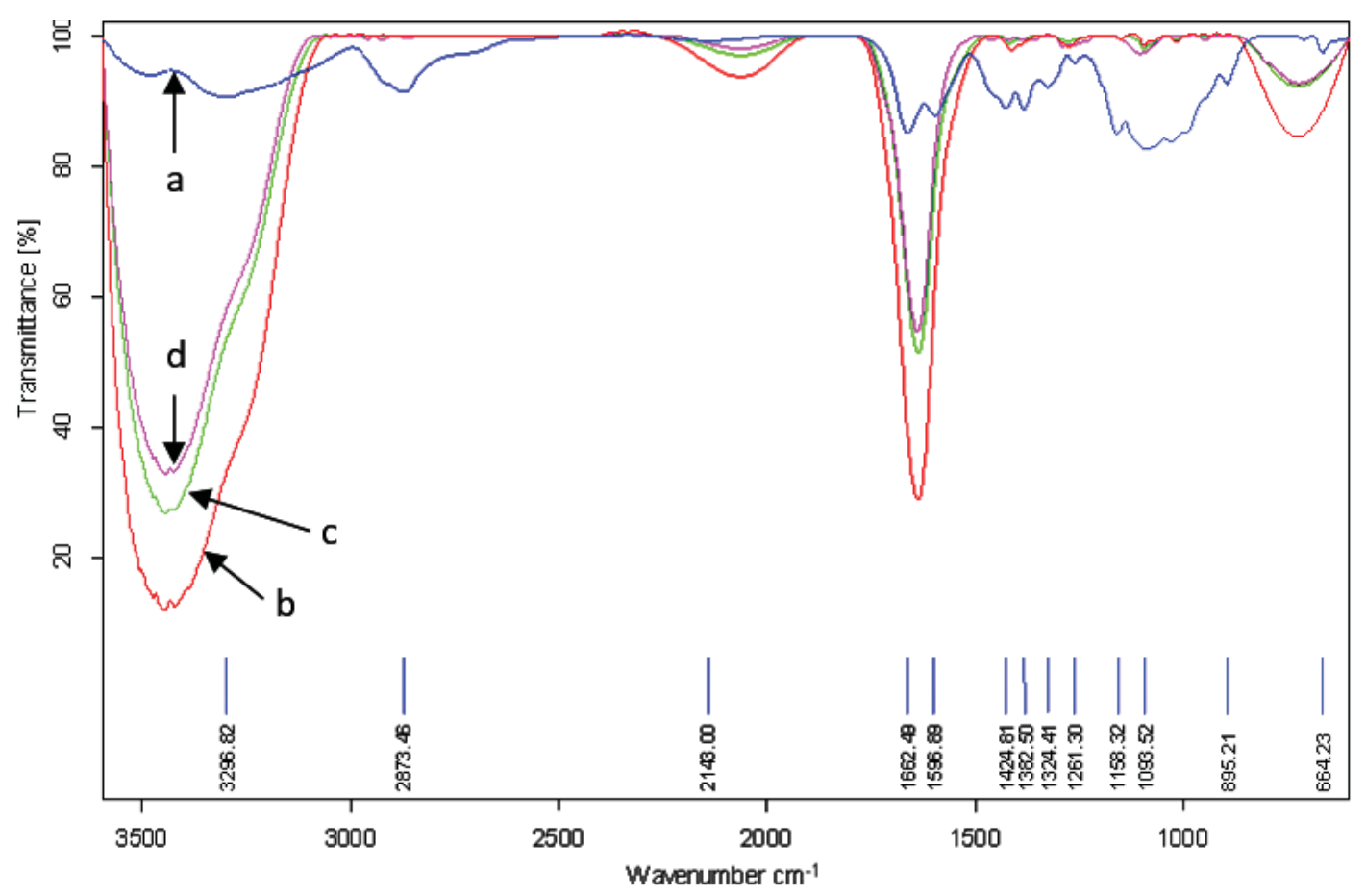

Figure 2. FTIR spectra of (a) chitosan powder, (b) chitosan film, (c) chitosan film enriched with EOs, and (d) EOs. The peaks show that the hydroxyl groups and amino groups of the chitosan might be involved in some interactions after incorporation of EOs to the chitosan.

solution indicating the interaction between chitosan and EOs. The present results indicate that blend of thyme and oregano EOs might be incorporated into the chitosan film.

\subsection{Antibacterial Activity}

The combined EOs and chitosan solution exhibited a bactericidal effect against all bacterial strains with a variable degree of susceptibility. The MIC and MBC of EOs, CFs, and CFs enriched with EOs against Escherichia coli, Staphylococcus aureus, Lactobacillus rahmnosus and Enterococcus faecium are shown in Table 2. The MIC and MBC values for EOs, CFs, and CFs enriched with EOs against Escherichia coli and
Staphylococcus aureus is very low compared to the concentrations needed to inhibit the growth of beneficial bacteria, Lactobacillus rahmnosus and Enterococcus faecium. However, a combination of CFs enriched with EOs exhibited a strong antibacterial properties against Escherichia coli $\left(\mathrm{MIC}=0.625 \mathrm{mg} \cdot \mathrm{mL}^{-1}, \mathrm{MBC}=1.25\right.$ $\mathrm{mg} \cdot \mathrm{mL}^{-1}$ ), while the inhibition was very low with $\mathrm{CFs}$ without $\mathrm{EOs}\left(\mathrm{MIC}=2.5 \mathrm{mg} \cdot \mathrm{mL}^{-1}, \mathrm{MBC}=5 \mathrm{mg} \cdot \mathrm{mL}^{-1}\right)$.

The useful Gram-positive bacteria, Lactobacillus rahmnosus and Enterococcus faecium were more resistant to EOs, CFs, and CFs enriched with EOs. The MIC of EOs and CFs were $25 \mu \mathrm{L} \cdot \mathrm{mL}^{-1}$ and $5 \mathrm{mg} \cdot \mathrm{mL}^{-1}$, while the MBC were more than $25 \mu \mathrm{L} \cdot \mathrm{mL}^{-1}$ and 10 mg. $\mathrm{mL}^{-1}$, respectively. When the CFs was enriched

Table 2. MIC ( $\left.\mu \mathrm{L} \cdot \mathrm{mL}^{-1}\right)$ and MBC $\left(\mu \mathrm{L} \cdot \mathrm{mL}^{-1}\right)$ of the essential oils (EOs), chitosan film solution (CFs), and chitosan film solution enriched with EOs $(\mathrm{CFs}+\mathrm{EOs})^{\mathrm{a}}$.

\begin{tabular}{lllllll}
\hline \multirow{2}{*}{ Bacteria } & \multicolumn{2}{l}{ EOs } & \multicolumn{2}{c}{ CFs } & \multicolumn{2}{c}{ CFs+Eos } \\
\cline { 2 - 7 } & MIC & MBC & MIC & MBC & MIC & MBC \\
\hline Escherichia coli & 0.39 & 0.78 & 2.5 & 5 & 0.625 & 1.25 \\
Staphylococcus aureus & 12.5 & 25 & 2.5 & 5 & 2.5 & 5 \\
Lactobacillus rahmnosus & 25 & $>25$ & 5 & $>10$ & 5 & $>10$ \\
Enterococcus faecium & 25 & $>25$ & 5 & $>10$ & 2.5 & 5 \\
\hline
\end{tabular}


Table 3. MIC ( $\left.\mu \mathrm{L} \cdot \mathrm{mL}^{-1}\right)$ and MFC $\left(\mu \mathrm{L} \cdot \mathrm{mL}^{-1}\right)$ of the essential oils (EOs), chitosan film solution (CFs), and chitosan film solution enriched with EOs (CFs+EOs) $)^{\mathrm{a}}$.

\begin{tabular}{lllllll}
\hline \multirow{2}{*}{ Fungi } & \multicolumn{2}{c}{ EOs } & \multicolumn{3}{c}{ CFs } & \multicolumn{3}{c}{ CFs+EOs } \\
\cline { 2 - 7 } & MIC & MFC & MIC & MFC & MIC & MFC \\
\hline Asprgillus niger & 12.5 & 25 & $>10$ & $>10$ & $>10$ & $>10$ \\
Alternaria alternata & 12.5 & 25 & $>10$ & $>10$ & 5 & 10 \\
\hline
\end{tabular}

with EOs, the MIC was reduced to $2.5 \mathrm{mg} \cdot \mathrm{mL}^{-1}$ and the bactericidal concentration was $5 \mathrm{mg} \cdot \mathrm{mL}^{-1}$ against Enterococcus faecium, while against Lactobacillus rahmnosus the MIC was $5 \mathrm{mg} \cdot \mathrm{mL}^{-1}$ and the bactericidal concentration was $>10 \mathrm{mg} \cdot \mathrm{mL}^{-1}$.

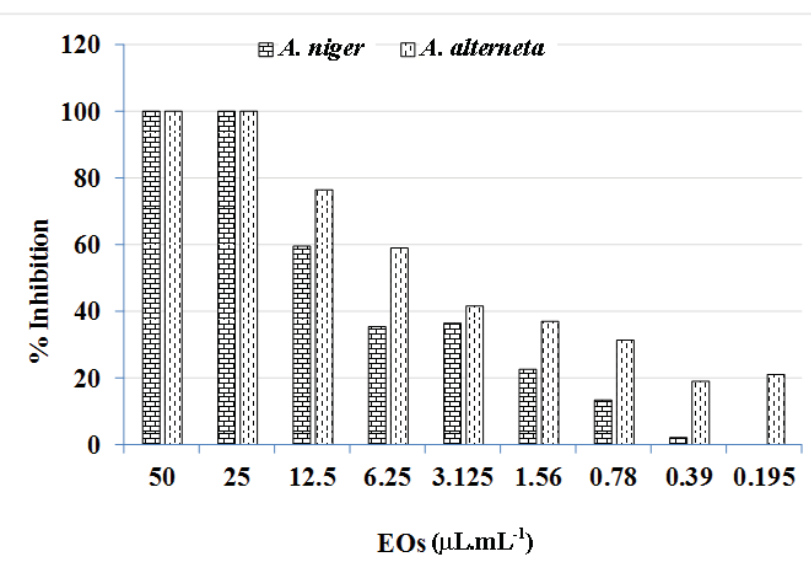

Figure 3. The percentage of microbial growth inhibition carried out against Aspergillus niger and Alternaria alternata by a blend of Thyme and Oregano essential oils.

\subsection{Antifungal Activity}

The results obtained on the effect of the blend of thyme and oregano EOs, CFs, and the combination of CFs with EOs has shown a significant inhibitory activity on the growth of Aspergillus niger and Alternaria alternata. These two fungi exhibited the same susceptibility to EOs with MIC of $12.5 \mathrm{mg} \cdot \mathrm{mL}^{-1}$ and MFC of $25 \mathrm{mg} \cdot \mathrm{mL}^{-1}$ (Table 3). In contrast, both Aspergillus niger and Alternaria alternata were found not to be sensitive to CFs at all concentrations (MIC and MFC $>10 \mathrm{mg} \cdot \mathrm{mL}^{-1}$ ). The percent inhibition of the two strains, Aspergillus niger and Alternaria alternata by EOs is shown in Figure 3. For all the fungal strains, the MFC that results into no fungal growth on the plates was found to be $25 \mu \mathrm{L} . \mathrm{mL}^{-1}$, while the growth inhibition was observed even with the smallest concentrations $\left(0.39\right.$ and $0.195 \mu \mathrm{L} . \mathrm{mL}^{-1}$ respectively for Aspergillus niger and Alternaria alternata. Alternaria alternata seems to be more sensitive than Aspergillus niger.

Chitosan in solution without EOs does not show an inhibitory effect against Aspergillus niger at all concentrations (Fig. 4). Considering CFs enriched with the EOs, as the concentration was increased,
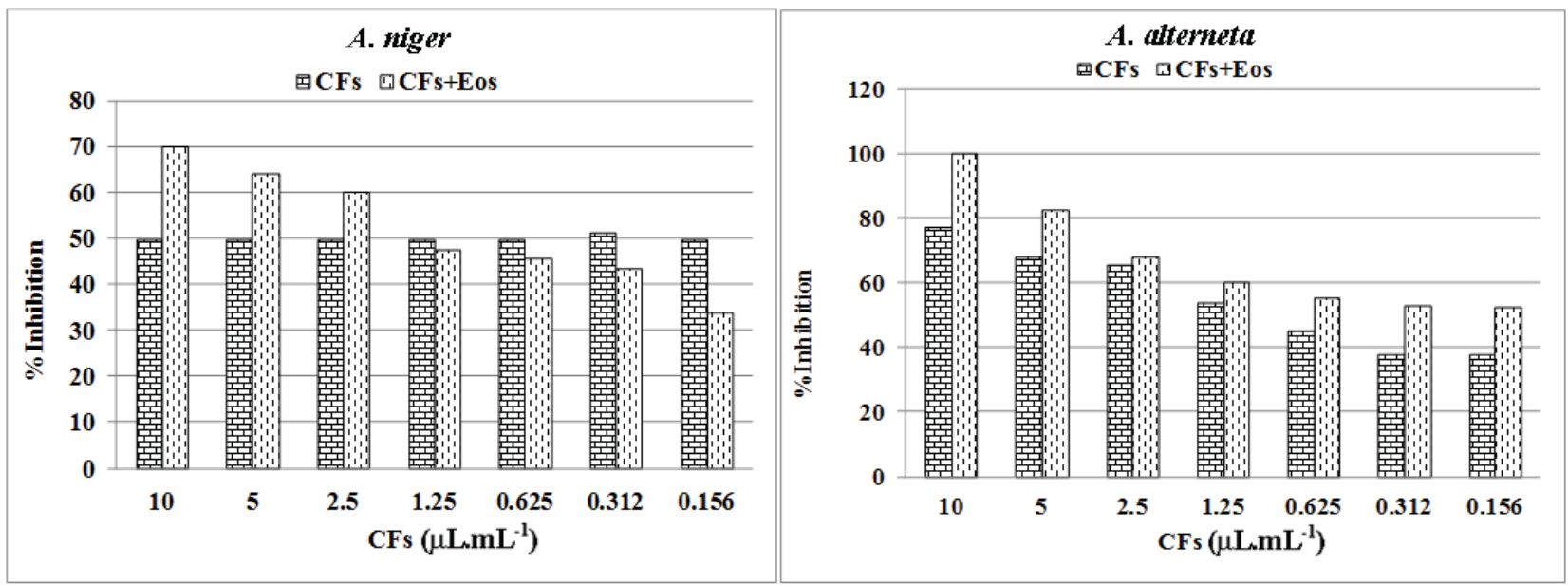

Figure 4. The percentage of microbial growth inhibition carried out against Aspergillus niger and Alternaria alternata by $\mathrm{CFs}$ and $\mathrm{CFs}+\mathrm{EO}$ s solutions. 
the antifungal effect was also exacerbated. At the concentration of $10 \mu \mathrm{L} . \mathrm{mL}^{-1}$ of the EOs and $10 \mathrm{mg} \cdot \mathrm{mL}^{-1}$ of chitosan in the film solution, no fungal growth (100\% inhibition) was noticed and the inhibition activity was observed against all the fungal strains even with the smallest concentrations of chitosan and EOs in the solution.

\section{Discussion}

When Thyme and Oregano EOs are mixed, FTIR spectra revealed characteristics peaks at 1638 (amide I) and 723 (C-O stretching) resulting from many peaks found in the individual $\mathrm{EO}$ which merged to a single peak. However, the $\mathrm{OH}$ and $\mathrm{N}-\mathrm{H}$ stretching bands around $3443 \mathrm{~cm}^{-1}$ remained undisturbed when the mixture of EOs are added to the chitosan film solution. This is consistent with the results of Hosseini et al. (16) that have recorded the same characteristic peaks in the FTIR spectra of the oregano EO at the same wave number in the EO-loaded chitosan nanoparticles indicating no modification or interaction between this EO and chitosan nanoparticles. In the present study, a shift from 3296 to $3443 \mathrm{~cm}^{-1}$ is found in the EOs-loaded chitosan film solution indicating that the hydrogen bonding was affected by the binding of EOs to the chitosan. Similar results were reported by Regiel et al. (32) when chitosan in solution was chemically crosslinked with the silver. According to Hosseini et al. (16), the binding of the EO to chitosan in solution results in a marked increase in the intensity of the $\mathrm{CH}$ stretching peaks which indicates an increase in the content of ester groups coming from EO molecules.

It is well known that CFs exhibit antibacterial activity due to their well-developed surface, which provides maximum contact with the bacteria (31). The $\mathrm{MIC}$ and $\mathrm{MBC}$ values for EOs, CFs, and $\mathrm{CFs}$ enriched with EOs against Escherichia coli and Staphylococcus aureus is very low compared to the concentrations needed to inhibit the growth of useful bacteria such as Lactobacillus rahmnosus and Enterococcus faecium. In similar studies, Rodríguez-Núñez et al. (29) have reported a larger bactericidal effect of chitosan film solution against Gram-negative bacteria (Salmonella typhimurium) than Gram-positive (Staphylococcus aureus) bacteria; results that are consistent with those found in the present study. In this study, CFs enriched with EOs presented a strong antibacterial property against Escherichia coli, while the inhibition was very low with CFs alone (i.e., without EOs). Our observation is in agreement with the results obtained by other authors on the chitosan film with a similar degree of deacetylation; with preparation conditions either similar or different (30-32).

This study has revealed that the useful Grampositive bacteria, Lactobacillus rahmnosus and Enterococcus faecium were more resistant to EOs, CFs, and CFs enriched with EOs. It has been previously reported by López-Mata et al. (30) that chitosan films incorporated with carvacrol has high bactericidal property against the two major Gram-negative food contaminant pathogenic bacteria (i.e., Escherichia coli and Salmonella typhimurium). Carvacrol is a phenolic compound found in essential oils of oregano and thyme, possessing antimicrobial and antioxidants properties $(1-2,28)$. Chitosan has the ability to bind and improve the bioactive components and bactericidal activities of EOs (16). The high antibacterial activity that was recorded against pathogenic bacteria in the present study could be explained by the fact that the positively charged chitosan enriched with EOs can create a semipermeable barrier capable of reducing respiration and microbial growth retardation $(29-30,33)$. This result can also be explained by the direct contact between the bacteria and the chitosan-EOs films which could establish the electrostatic bond between the negatively charged bacterial wall and cationic chitosan which has demonstrated a superior antibacterial action (33). The antibacterial mechanism of carvacrol has been studied already and it is known that such antibacterial property is due to the changes caused by the interaction with lipophilic components of the bacterial membrane. This interaction causes a change in the permeability of $\mathrm{H}+$ and $\mathrm{K}+$, disrupts enzyme system, compromises the genetic material of the bacteria, form fatty acid hydroperoxide by the oxygenation of unsaturated fatty acid, damages the essential functions and causes bacteria death (33-34).

The present results have revealed a significant inhibitory activity of the blend of thyme and oregano EOs, CFs, and CFs enriched with EOs on the growth of Aspergillus niger and Alternaria alternata. These results are in line with those previously reported by Kaur et al. (25), who have shown that antifungal activity of the chitosan nanoparticles against Aspergillus flavus, Alternaria alternata and Rhizoctonia solani was enhanced when chitosan nanoparticles were loaded with metals like $\mathrm{Cu}$ and $\mathrm{Zn}$ compared to the nanoparticles of chitosan alone. The antifungal effect of CFs enriched with EOs was strengthened as the concentration was increased. This is consistent with the results of Prabu and Natarajan, (35) who have previously reported that the antifungal effect of chitosan isolated from Padophthalmus vigil was strengthened as the concentration was increased. Comparing these 
results with the one obtained in the present study, it could be deduced that the value obtained for the fungal growth inhibition is slightly higher in our investigation compared to those of the previous reports $(25,35)$; differences probably being due to the higher deacetylation degree of the used chitosan and the presence of EOs in the CFs.

In conclusion, this study has evaluated the antimicrobial effect of the chitosan films solution enriched with EOs against two pathogenic bacteria (Staphylococcus aureus and Escherichia coli), two useful bacteria (Enterococcus faecium and Lactobacillus rahmnosus), as well as two molds fungi (Aspergillus niger and Alternaria alternata). It is interesting that we could find that pathogenic bacteria are more susceptible to antibacterial agents compared to the useful bacteria. It was also observed that, antimicrobial activities were enhanced when chitosan film solution was enriched through preparation of a blend of chitosan with thyme and oregano essential oils compared to the chitosan film solution alone. These results show that chitosanEOs complexes could be the promising candidates as a potent antimicrobial inhibitory agent that could be used as a coating for the monogastric animal feeds.

\section{Acknowledgements}

We gratefully thank the research facility at NIGEB, Iran for antimicrobial and FTIR analysis. Mr Kana Jean Raphaël acknowledges the fellowship received from TWAS-UNESCO Associateship Scheme at Centres of Excellence in the South.

\section{References}

1. Bento MHL, Ouwehand AC, Tiihonen K, Lahtinen S, Nurminen P, Saarinen MT, Schulze H, Mygind T, Fischer J. Essential oils and their use in animal feeds for monogastric animals - Effects on feed quality, gut microbiota, growth performance and food safety: a review. Vet Med. 2013; 58(9): 449-458.

2. Krishan G, Narang A. Use of essential oils in poultry nutrition: A new approach. J Adv Vet Anim Res. 2014; 1(4): 156-162. DOI: 10.5455/javar.2014.a36

3. Chao SC, Gary YD. Screening for inhibitory activity of essential oils on selected bacteria, fungi and viruses. $J$ Essent Oil Res. 2000; 12: 639-649. DOI: 10.1080/10412905.2000.9712177

4. Cross DE, McDevitt RM, Hillman K, Acamovic T. The effect of herbs and their associated essential oils on performance, dietary digestibility and gut microflora in chickens from 7 to 28 days of age. Brit Poult Sci. 2007; 48: 496-506. DOI: 10.1080/00071660701463221

5. Kirsti T, Kettunen H, Bento MHL, Saarinen M, Lahtinen S, Ouwehand AC, Schulze H, Rautonen N. The effect of feeding essential oils on broilerperformance and gutmicrobiota.BritPoult Sci. 2010; 51: 381-392. doi: 10.1080/00071668.2010.496446

6. Cao PH, Li FD, Li YF, Ru YJ, Péron A, Schulze H, Bento H. Effect of essential oils and feed enzymes on performance and nutrient utilization in broilers fed a corn/soy-based diet. Int $J$ Poult Sci. 2010; 9(8): 749-755. doi: 10.3923/ijps.2010.749.755

7. Khattak F, Ronchi A, Castelli P, Sparks N. Effects of natural blend of essential oil on growth performance, blood biochemistry, cecal morphology, and carcass quality of broiler chickens. Poult Sci. 2014; 93: 132-137. DOI: 10.3382/ps.2013-03387

8. Tiihonen K, Kettunen H, Bento MHL, Saarinen M, Lahtinen S, Ouwehand AC, Schulze H, Rautonen N. The effect of feeding essential oils on broiler performance and gut microbiota. Brit Poult Sci. 2010; 51(3): 381-392. DOI: 10.1080/00071668.2010.496446

9. Amerah AM, PE'Ron A, Zaefarian F, Ravindran V. Influence of whole wheat inclusion and a blend of essential oils on the performance, nutrient utilisation, digestive tract development and ileal microbiota profile of broiler chickens. Brit Poult Sci. 2011; 52(1): 124-132. DOI: 10.1080/00071668.2010.548791

10. Zhang KY, Yan F, Keen CA, Waldroup PW. Evaluation of microencapsulated essential oils and organic acids in diets for broiler chickens. Int J Poult Sci. 2005; 4(9): 612-619. DOI:10.3923/ijps.2005.612.619

11. Šegvić Klarić M, Kosalec I, Mastelić J, Piecková E, Pepeljnak S. Antifungal activity of thyme (Thymus vulgaris L.) essential oil and thymol against moulds from damp dwellings. Lett Appl Microb. 2007; 44: 36-42. DOI: 10.1111/j.1472765X.2006.02032.X

12. Tullio V, Nostro A, Mandras N, Dugo P, Banche G, Cannatelli MA, Cuffini AM, Alonzo V, Carlone NA. Antifungal activity of essential oils against filamentous fungi determined by broth microdilution and vapour contact methods. J Appl Microb. 2007; 102: 1544-1550. DOI: 10.1111/j.1365-2672.2006.03191.x

13. Brenes A, Roura E. Essential oils in poultry nutrition: main effects and modes of action. Anim Feed Sci Technol. 2010; 158: 1-14. DOI:10.1016/j.anifeedsci.2010.03.007

14. Bassolé IHN, Juliani HR. Essential oils in combination and their antimicrobial properties. Molecules 2012; 17: 3989-4006. DOI: 10.3390/molecules17043989

15. Bustos R, Romo L, Yáñez K, Díaz G, Romo C. Oxidative stability of carotenoid pigments and polyunsaturated fatty acids in microparticulates diets containing krill oil for nutrition of marine fish larvae. J Food Engin. 2003; 56: 289-293. DOI: 10.1016/S0260-8774(02)00272-8

16. Hosseini SF, Zandi M, Rezaei M, Farahmandghavi F. Two-step method for encapsulation of oregano essential oil in chitosan nanoparticles: preparation, characterization and in vitro release study. Carbohyd Poly. 2013; 95: 50-56. DOI: 10.1016/j. carbpol.2013.02.031

17. Fernández-Urrusuno R, Calvo P, Remuñan-López C, Vila-Jato JL, Alonso MJ. Enhancement of nasal absorption of insulin using chitosan nanoparticles. Pharm Res. 1999; 16(10):157681. DOI: $10.1023 / \mathrm{A}: 1018908705446$

18. Vila A, Sánchez A, Janes K, Behrens L, Kissel T, Vila-Jato JL, Alonso MJ. Low molecular weight chitosan nanoparticles as new carriers for nasal vaccine delivery in mice. Eur $J$ Pharm Biopharm. 2004; 57(1):123-31. DOI: 10.1016/j. ejpb.2003.09.006

19. Rezaei Mokarram A, Alonso MJ. Preparation and evaluation of chitosan nanoparticles containing diphtheria toxoid as new carriers for nasal vaccine delivery in mice. Arch Razi Inst. 2006; 61(1):13-25.

20. Mohammadpour Dounighi N, Behfar A, Ezabadi A, Zolfagharian $\mathrm{H}$, Heydari M. Preparation of Chitosan nanoparticles containing 
Naja-naja oxiana snake venom. Nanomedicine, 2010; 6(1):13743. DOI: 10.1016/j.nano.2009.06.002

21. Mohammadpour Dounighi N, Eskandari R, Avadi MR, Zolfagharian H, Mir Mohammad Sadeghi A, Rezayat M. Preparation and in vitro characterization of chitosan nanoparticles containing Mesobuthus eupeus scorpion venom as an antigen delivery system. $J$ Verno Anitox Trop Dis. 2012; 18(1): 44-52. DOI: 10.1590/S1678-91992012000100006

22. Qi L, Xu Z, Jiang X, Hu C, Zou X. Preparation and antibacterial activity of chitosan nanoparticles. Carboh Res. 2004; 339: 2693-2700. doi:10.1016/j.carres.2004.09.007

23. New N, Furuike T, Tamura H. The mechanical and biological properties of chitosan scaffolds for tissue regeneration templates are significantly enhanced by chitosan from Gongronella butleri. Materials 2009; 2(2): 374-398. DOI:10.3390/ma2020374

24. Wei D, Sun W, Qian W, Ye Y, Ma X. The synthesis of chotosanbased sliver nanoparticles and their antibacterial activity. Carboh Res. 2009; 344: 2375-23. DOI: 10.1016/j.carres.2009.09.001

25. Kaur P, Thakur R, Barnela M, Chopra M, Manuja A, Chaudhury A. Synthesis, characterization and in vitro evaluation of cytotoxicity and antimicrobial activity of chitosan-metal nanocomposites. J Chem Technol Biotech. 2015; 90(5): 867873. DOI: $10.1002 /$ jctb.4383

26. Vimal S, Abdul Majeed S, Taju G, Nambi KSN, Sundar Raj N, Madan N, Farook MA, Rajkumar T, Gopinath D, Sahul Hammed AS. Chitosan tripolyphosphate (CS/TPP) nanoparticles: Preparation, characterization and application for gene delivery in shrimp. Act Trop. 2013; 128: 486-493. DOI: 10.1016/j.actatropica.2013.07.013

27. Vimal S, Taju G, Nambi KSN, Abdul Majeed S, Sarath Babu V, Ravi M, Sahul Hammed AS. Synthesis and characterization of CS/TPP nanoparticles for oral delivery gene in fish. Aquaculture, 2012; 358/359: 14-22. DOI:10.1016/j.aquaculture.2012.06.012

28. Chi S, Zivanovic S, Penfield MP. Application of chitosan films enriched with oregano essential oil on Bologna-active compounds and sensory attributes. Food Sci Technol Int. 2006; 12(2):111-117.

29. Rodríguez-Núñez JR, López-Cervantes J, Sanchez-Machado DI, Ramirez-Wong B, Torres-Chavez P, Cortez-Rocha MO. Antimicrobial activity of chitosan-based films against Salmonella typhimurium and Staphylococcus aureus. Int $J$ Food Sci Tech. 2012; 47: 2127-2133. DOI: 10.1111/j.13652621.2012.03079.x. (C) 2012

30. Lopez-Mata MA, Ruiz-Cruz S, Silva-Beltran NP, Ornelas-Paz JJ, Zamudio-Flores PB, Burruel-Ibarra SE. Physicochemical, antimicrobial and antioxidant properties of chitosan films incorporated with Carvacrol. Molecules 2013; 18: 1373513753. DOI: 10.3390/molecules 181113735

31. Leceta I, Guerrero P, Ibarburu I, Duenas MT, De la Caba K. Characterization and antimicrobial analysis of chitosan-based films. J Food Eng. 2013; 116: 889-899. DOI: 10.1016/j. jfoodeng.2013.01.022

32. Regiel A, Irusta S, Kyziol A, Arruebo M, Santamaria J. Preparation and characterization of chitosan-silver nanocomposite films and their antibacterial activity against Staphilococcus aureus. Nanotechnology 2013; 24: 1-13. DOI: 10.1088/0957-4484/24/1/015101

33. Ruiz-Navajas Y, Viuda-Martos M, Sendra E, Perez-Alvarez JA, Fernandez-Lopez J. In vitro antibacterial and antioxidant properties of chitosan edible films incorporated with Thymus moroderi or Thymus piperella essential oils. Food Cont. 2013; 30: 386-392. DOI: 10.1016/j.foodcont.2012.07.052

34. Ultee SA, Bennik M, Moezelaar R. The phenolic hydroxyl group of carvacrol is essential for action against the foodborne pathogen Bacillus cereus. Appl Environ Microb. 2002; 68: 1561-1568. DOI: 10.1128/AEM.68.4.1561-1568.2002

35. Prabu K, Natarajan E. In vitro antimicrobial and antioxidant activity of chitosan isolated from Podophthalmus vigil. J Appl Pharm Sci. 2012; 2(9): 75-82. DOI: 10.7324/ JAPS.2012.2916 